\title{
Schedule Planning Control of Software Project based on PSP
}

\author{
Yongchang Ren ${ }^{1, a}$, Chengwei $\mathrm{Wu}^{1, \mathrm{~b}}$, Ying Zhao ${ }^{2, \mathrm{c}}$ \\ ${ }^{1}$ College of Information Science and Technology, Bohai University, Jinzhou, 121013, China \\ ${ }^{2}$ Computer Center, Liaoning University of Technology, Jinzhou, 121001, China \\ a1213552916@qq.com, b357889057@qq.com, 'Igjsjzy8@163.com
}

Keywords: software project management; schedule planning; control process; control method; PSP; personal software process

\begin{abstract}
Favorable planed management is the base of software project succeed. In this piece aim at the present situation of software project management, comprehensive use the thought of software engineering and project management, explore process and method of project schedule planning control. On the base of analysis software project schedule planning control difficulties, research based on PSP method. PSP follow adjustment, practice, measurement, comparison result and readjustment such a circulation and the continuous improvement of process, it is a process step by step for a long time. This paper studies the successful application of content; it can change insufficient plan in software project management process, the phenomenon of control adverse, improve comprehensive management ability and competitive power of project, creating Value for software company, improve high quality service for user.
\end{abstract}

\section{Introduction}

Favorable planed management is the base of software projects succeed. But in actual implementation process, due to software project itself characteristics and some indeterminism factor, make the project progress can not proceed according to plan completely. For making sure project achieve the success, must proceed tracking control to the implementation of project scheduled planning [1].

Project schedule planning control is directing in implementation process after formulated project scheduled plan, proceed checking, contrasting, analysis and adjusting for the condition of process, like actual schedule conform to design schedule, it indicate the condition of project finished in good condition, the schedule planning total goal realization has guarantee; if find actual schedule deviate from the design schedule, should analysis the reason of produce deviation and the effect of follow-up work project schedule plan total goal, find out the way to solve this problem and the measure which avoid schedule total goal affected, and on the basis of these methods and measures, proceed modifying to the original schedule plan, make it tally with the actual situation and make sure the original schedule plan can come true. And then proceed new checking, contrasting, analysis and adjusting again, until project final finished, thus make sure the schedule plan total goal realization, even can make the project completed ahead, in does not affect the premise of project complete quality and increase the project cost [2].

See from the project implementation results, can at a predetermined time, reach the expected work target. We can say the project get effective schedule plan control. See from the software project implementation process, effective schedule planning control should have the following characteristics: Project manager can real time control the project actual progress status, can foresee find and solve the problem of affect project progress in project implementation, can take effective method to control the element of affect project progress, project at a predetermined time to finish. For implement effective schedule control, manage need to understand the characteristics of software project and process and method of schedule planning control.

\section{Difficulties of Control}

Formulate the process of project schedule planning also called project planning, early in the project 
start-up phase, the project goals, scope and so on also is not very clear, but the project has already started, the project team has already started, already begin to make the work plan of project team. Now the plan formulation have prodigious "predict" element, amount to "plan". When project enter into essence on stage, mean contract signing, after completion of the demand analysis, project plan will be a very specific and strict examination task plan. By now it is not plot but plan. The difficulties of software project schedule planning mainly embodied in the following respects [3]:

(1) The uncertainty of the software project. When project planning, to the greatest extent to let the project team members estimate their period, make team members play an active part in the project, and as technology is developing very fast, developers often only to a few specific module part of the work have gained some understanding. But project manager also is not completely passive, can through accumulation project management data; promote the development process capability maturity improvement, in order to help developer for more and more accurate estimate of the project.

(2) Elusive and disperse of content of a project. The software project contents usually less specific than other projects, harder to concentrate collect. So, plan is asked for the form of combine text and graphics document appear. To schedule, resources decomposition, duties decomposition and goal decomposition etc, through project management software proceed planning and management, don't disperse in several parts of the document, like that very against synchronous modify. Project plan need to be designed the file of "checked", it asks for task division need specific to product. For example test, do not simply decompose to testing preparation, test execution, but decompose to test environment building, test scheme compilation, test execution, test report is good.

(3) It can't deal with the relationship between plan and change. We can't fix the plan in plan implementation process; proceed the periodically maintenance for plan in practical operation. Develop schedule planning is affected by many aspects, such as the affect of linked plan, actual schedule changes, resource change, project target change etc. With the requirement gradually clear it will cause the plan refinement, if maintenance development plans not in time, development plan and actual deviation will be bigger and bigger, finally become worthless. When changing plan, should keep old version, we need read information of old version in summary stage, so that evaluate the history of project process change.

(4) Not cultivate habit of work as planned. In real work, carry out project plan often encounter all kinds of difficulties. Many people think plan is a kind of restrain, anyhow work forward harder, and we no need for tie hands and feet by ourselves; Another condition is not according to plan work habits, project started before long, plan is put at the side completely; Still have a kind of situation is that source can't guarantee, sometimes equipment not ready, person is often transfer to take part in unplanned work, it's too late to change plan everyday, had to give up the plan.

\section{PSP Cost Control}

There are a lot of schedule plan control methods, in this paper research earned value management and PSP tow methods. Earned Value Management (EVM), is using with scheduled plan, cost budgeting, actual cost three associated independence variable, and it is a kind of method of proceeding project performance management and cost control [8]. It compares Plan workload, accomplishment of WBS (earn) and actual cost spend, Measure and calculate cost and schedule whether fit the original plan, then the cost control method. In this paper, study the method of PSP cost control.

Personal Software Process (PSP) is developed leader by S.Humphre in Carnegie Mellon University-the United States Software Engineering Institute (CMU/SEI), first published in 1995. PSP is a kind of self-improvement process which can be available to control, manage, and improve individuals work way, is a structured framework include software development form, guide and regulations, will statistical process control into software engineering, supply foundation for ration software engineering.

Project planning management is the base on project implementation. But at present business 
exist in the following problems on Plan Development, track and monitoring: Plan Development no reasonable reason, only depend on experience and implementation of program is very bad after production test phase, and track visualization effect range. In view of these situations, implement PSP in business and on the base of combining software project management, will the thought of personal planning management apply to project planning management, put forward project planning manage method based on PSP, this method based on process of project plan, the plan development based on historical data, and tracking principle based on working unit, solved the problem general exist in planning management.

PSP follow adjustment, practice, measurement, comparison result and readjustment such a circulation and the continuous improvement of process, it is a process step by step for a long time. For realizing this process, it provides a whole set of method coordinate with it in PSP framework, uses to help software developer finish their works, and mainly includes: project estimation, formulation and tracking of project plan, measurement and improvement of product quality etc.

PSP framework similar to CMM, divide improve process into four levels: individual baseline process, individual planning process, individual quality management and individual cycle process, through PSP software engineer accumulated rich experience on workload estimation, plan development, tracking and monitoring etc, laid the foundation for follow-up implementation process.

The planning management method based on PSP, it asks for each developer fill in work log everyday, talking about Graphs and Trends every week. Software development team ordinary according to project cycle, weekly meets a project meeting, in order to tracking and monitoring of project scheduled condition. Suppose a project team has a project manager, several development teams under the team, tracking and monitoring process of typical project plan as shown in Fig. 1 shows [11] .

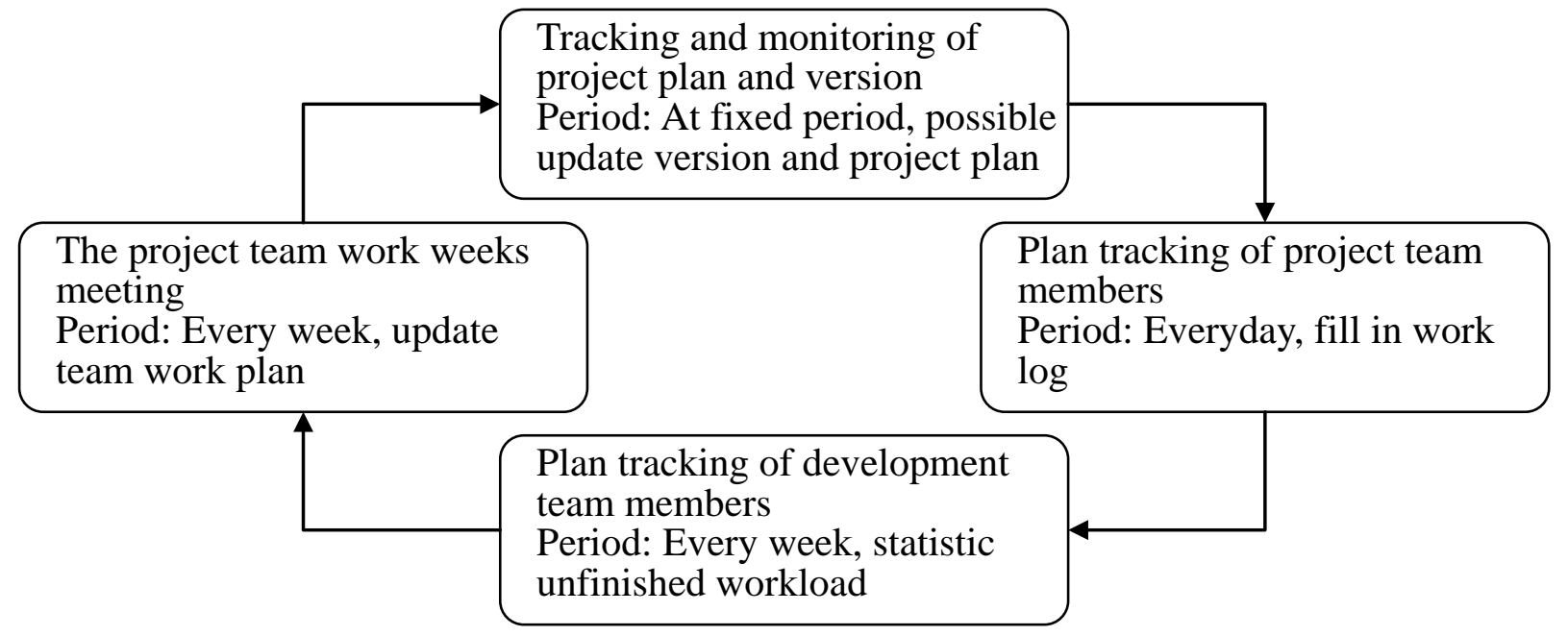

Fig. 1. Tracking and monitoring process of project plan

For how to fill the work log in the figure, main fill in the work load which have been finished in the same day, talking about Graphs and Trends every weekend, key fill out the unfinished work, we can finish the collection and clear up of data through tools.

Practice and theory make clear that use unfinished workload to calculate plan completion rate based on work unit is more accuracy than based on has finished workload. Calculate unfinished workload, may be due to the content of think omit or can also refinement when draw up a plan, all can take into account at this time, along with all the others as the unfinished work statistics, and update team development plan.

\section{Conclusion}

At present, we usually use three method to plan and control the software project at home and abroad [12]: One is the manager rely on the successful experience to formulate scheduled plan and control 
implementation process; The second is that follow relevant standards and guidelines, like SPMP of IEEE (Standard for Software Project Management Plans) and CMM/PSP/TSP software process improvement system of Carnegie Mellon University-the United States Software Engineering Institute; the third is that use support Tools, like Microsoft Project 2002, Primavera Project Planner and All Fusion Process Management Suite etc. From the research situation at home and abroad to look, focus of concern mainly focuses on the aspect of the standard and tools of software project planning control, lack of system research on the specific methods and process in the plan control process.

This paper from the reality of software project management, explore process and method of software project scheduled plan management, be aimed at changing the lack in project management process, the phenomenon of control poor, to improve the comprehensive management ability and competitive power of project, to create value for software business, to offer satisfactory service for user.

\section{Acknowledgement}

This work is supported by 2014 general subject of colleges and universities scientific research of Liaoning province (L2014248): Emergency Disposal on Urban Water Supply Pipe Network Accident Based on FCR Computer Reasoning.

\section{References}

[1] G..J. Liu, "The 21th Century New Project Management," Tsinghua University Press, 2003.

[2] H.M. Zeng, "Schedule Plan and Schedule Control of JD Smart Card Applying System," Master's degree of Southwest Jiaotong University, 2007.

[3] Y.C. Ren, T. Xing, X. E, "Software Development Process Management," Beijing Jiaotong University Press, 2010.

[4] A.M. Dai, T.J. Li, L.J. Xiao, "Research on ERP implementation project schedule control Based on Network Plan Technology," China Management Informationization, vol. 12, no. 12, pp. 64-67, 2009.

[5] Y.N. Li, "Project Time Management and Its Applications of Project Management Software," China Machine Press, 2007.

[6] S.C. Cheng, "Research of Key Technologies of Project Planning and Scheduling for Aerospace Model Engineering Project," Master's degree of Northwestern Polytechnical University, 2006.

[7] D.F. Xie, "Research on Project Schedule Management for New Library Construction of Ocean University of China," Master’s degree of Ocean University of China, 2009.

[8] Y.C. Ren, T. Xing, "Research on Method of Software Development Costs Control Based on Earned Value Management," China Management Informationization, vol. 10, no. 10, pp. 33-25, 2007.

[9] J.H. Zhang, "Software Project Management," China Machine Press, 2005.

[10] Y.W. Chen, "Achieve of Software Engineering Project Management Cost / Schedule Plan Control," Journal of Wuhan Institute of Chemical Technology, vol. 27, no. 4, pp. 88-91, 2005.

[11] Y. Fan, "An Improved Approach to Software Project Plan Management," Journal of Nanjing University (natural sciences edition), vol. 41, no. 10, pp. 699-703, 2005.

[12] B. Kuang, "Research on Software Project Management Planning and Control Method," Master's degree of Guizhou University, 2006. 